\title{
Preparation of high fischer ratio oligopeptide of chlorella powder using specific enzymatic hydrolysis
}

\author{
Ke XIONG ${ }^{1,2 *}$ (D), Jia-yun LIU ${ }^{1,3}$, Xiao-yi WANG ${ }^{1,2}$, Bao-guo SUN ${ }^{1,4}$, Zhi-yao ZHAO ${ }^{1,2}$, Peng-gang PEI ${ }^{2,4}$, Xiu-yuan LI $^{1,2}$
}

\section{Abstract Graphics}
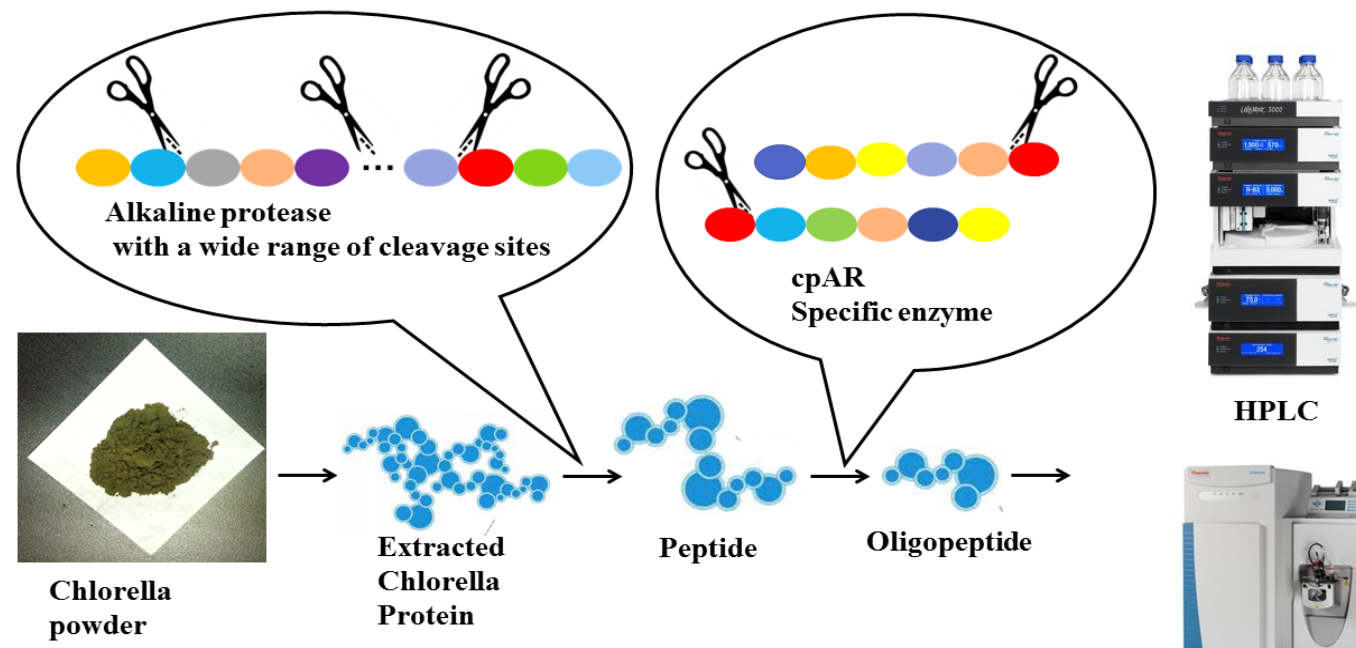

HPLC

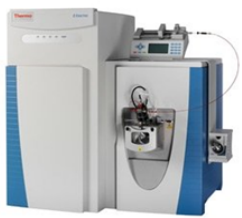

LC-ESI-MS

\begin{abstract}
Enzymatic hydrolysis of chlorella powder is a promising process to prepare high Fischer ratio oligopeptides (HFOPs). However, the relationship between Fischer ratios and enzymatic hydrolysis approaches remains poorly understood. In HFOPs production, directed enzymatic hydrolysis to release aromatic amino acids may be an effective way to increase Fischer ratio. The mutant carboxypeptidase from Aspergillus niger M00988 (cpAR), which has good specificity for hydrophobic amino acids in terminal peptidolysis, and commonly used papain and flavourzyme have been used to prepare HFOPs in this study. cpAR enzyme, flavourzyme The results show that the use of cpAR enzyme can increase the Fischer ratio. With chlorella powder as the raw material, alkaline protease and cpAR enzyme were used for two-step hydrolysis, and then activated carbon adsorption and ultrafiltration were used to prepare HFOPs. The Fischer ratio of oligopeptides reached 37.39, the length of the peptide chain was mainly distributed around 7-9 amino acids.
\end{abstract}

Keywords: chlorella powder; enzymatic hydrolysis; hydrophobic amino acids; high Fischer ratio; oligopeptides.

Practical Application: Chlorella powder can be used to prepare high Fischer ratio oligopeptides. After optimizing the conditions for chlorella protein extraction, the protein extraction rate reached $11.20 \%$. CpAR enzyme has high specificity for aromatic amino acids and can be used to prepare oligopeptides with high Fischer ratio. Fischer ratio of oligopeptides obtained by enzymatic hydrolysis of chlorella powder with alkaline protease and CpAR reached 37.39, and the peptide size was mainly distributed around 7-9 amino acids. 


\section{Introduction}

Rapid economic, scientific, and technological developments have improved human living standards. However, industrialization also had negative effects, including the increased pollution of air and water sources, and the consequent deterioration of human living environments (Appannagari, 2017). In addition, intense and fast-paced modern lifestyles have given rise to large numbers of sub-healthy people, and the numerous dietary requirements associated with a variety of chronic diseases have spurred an interest in the close relationship between health and diet (Zhang et al., 2019). Previously, it was generally believed that protein, an important dietary nutrient, would be broken down into free amino acids in the digestive tract for absorption and utilization by the body. However, recent studies have shown that proteins are absorbed as oligopeptides as well as amino acids (Shen \& Matsui, 2017). Compared with amino acid or protein absorption, oligopeptide absorption does not require digestion. The HFOPs are a kind of functional oligopeptides. Fischer ratio is the ratio of moles of branched chain amino acid content to aromatic amino acid content. Due to their unique amino acid composition and physiological functions, HFOPs have received significant attention from the food and pharmaceutical industries.

HFOPs are small peptides that contain relatively high levels of branched-chain amino acids and relatively low levels of aromatic amino acids. Several studies have shown that HFOPs have beneficial physiological effects, including antifatigue (Wang et al., 2019b), antioxidation (Ichikawa et al., 2012), and anticoagulation (Ren et al., 2016); these oligopeptides may also provide liver protection, treat hepatic encephalopathy (Kamalinejad et al., 2018) and phenylketonuria (Li et al., 2019).

Worldwide, HFOPs are typically produced via enzymatic hydrolysis. When HFOPs are enzymatically prepared, it is necessary to analyze the characteristics of raw protein material, and to optimize the preparation conditions. Xu et al. (2012) studied the preparation of HFOPs from egg white protein by enzymatic hydrolysis with alcalase and enzymes II. Du et al. (2014) used pepsin and flavourzyme to prepare HFOPs using minced tuna as the raw material. Thus, different enzyme combinations have successfully been used to produce oligopeptides with high Fischer ratios from various source materials. This implies that each enzyme system is limited and can only be used to prepare HFOPs from specific protein materials. However, the enzymes chosen are different for the same source material.To prepare HFOPs from corn gluten meal, Xu et al. (2017) preferred alkaline protease and papain; and Noguchi et al. (2016) selected $\alpha$-chymotrypsin and carboxypeptidase A.

At present, most studies on the preparation of HFOPs combine various enzymes to generate high Fischer ratios, but less consideration is given to the effects of enzyme specificity on the preparation process. Here, themutant carboxypeptidase from Aspergillus niger M00988 (cpAR), which has a high specificity for aromatic and hydrophobic amino acids, was selected for the preparation of HFOPs. The performance of cpAR was compared to that of other, less specific exopeptidases
Table 1. The basic composition and content of chlorella.

\begin{tabular}{lc}
\hline \multicolumn{1}{c}{ basic composition } & content $^{*}(\mathrm{~g})$ \\
\hline protein & 625 \\
Crude fiber & 22 \\
carbohydrate & 140 \\
fat & 31 \\
Moisture & 40 \\
Ash & 50 \\
Chlorophyll & 38 \\
\hline
\end{tabular}

*The amount contained in $1 \mathrm{~kg}$ of chlorella.

in order to determine the effects of exopeptidase specificity on the preparation of HFOPs.

The raw materials from which HFOPs are produced are typically derived from animal and plant proteins, commonly including corn gluten meal, soy protein isolate, caseinate, and whey protein. However, few studies have investigated the preparation of HFOPs from microbial-derived proteins. Noguchi et al. (2016) showed that the protein content of Chlorella powder reached $60 \%$, similar to that of fishmeal or brewer's yeast and the specific ingredients are shown in Table 1; Chlorella powder had more crude protein than vegetable protein sources, including soybeans. High protein content is useful when preparing HFOPs. In addition, Chlorella has been shown to significantly lower blood pressure and serum cholesterol levels (Merchant \& Andre, 2001). Qi \& Kim (2017) showed that the polysaccharides of Chlorella had immunomodulatory functions.

Chlorella is a widely distributed, commonly available, photosynthetic, autotrophic microorganism with high protein content. This high-protein marine organism may have several untapped uses. For this reason, we use chlorella powder to prepare HFOPs. The effect of hydrolysis of recombinant exoprotease with high specificity on aromatic amino acid substrate on the preparation of HFOP was explored. We investigated the relationship between the high Fischer ratio and exoprotease specificity by characterizing the HFOPs prepared by enzymatic hydrolysis and activated carbon adsorption. Finally, the Fischer ratio, molecular weight distribution, and peptide sequence of the prepared oligopeptides were analyzed.

\section{Materials and methods}

\subsection{Materials}

Chlorella powder (protein content 63.36-63.98\%) was purchased from Wudi Green Strange Bioengineering Co., Ltd (Qingdao, China). Corn protein powder was purchased from Guagua Feed (Binzhou, China). Caseinate was purchased from Beijing Aoboxing Biotechnology Co., Ltd (Beijing, China). Alkaline protease, amylase, flavourzyme, papain and amyloglucosidase were purchased from Shanghai yuanye Bio-Technology Co., Ltd (Shanghai, China). Aspergillus niger M00988 was collected from laboratory preservation. The mutant carboxypeptidase from Aspergillus niger M00988 (cpAR) was obtained by recombinant 
expression and purification. The glycine at position 124 of the carboxypeptidase was mutated to arginine to obtain the cpAR enzyme, which has good specificity for hydrophobic amino acids in terminal peptidolysis. O-phthalaldehyde (OPA), trifluoroacetate, formic acid, acetonitrile, and methanol were purchased from Sigma (St. Louis, MO, USA). Amino acid standards (leucine, isoleucine, valine, phenylalanine and tyrosine) were purchased from Shanghai Yuan Wild Biotechnology Co., Ltd. (Shanghai, China). All other reagents were of analytical grade.

\subsection{Preparation of HFOPs}

The enzymatic preparation of HFOPs typically requires the following steps: pretreatment, endopeptidase action, exopeptidase action, separation and purification. In this study, we compared HFOPs prepared from Chlorella powder with HFOPs prepared from plant-derived corn gluten meal and animal-derived caseinate.

Because Chlorella has a hard cell wall, the cell wall must be broken prior to protein extraction (Gerken et al., 2013). First, we added a certain amount of deionized water to Chlorella powder and allowed the powder to swell for 12 hours at room temperature with shaking at $200 \mathrm{rpm}$. Then add solid sodium hydroxide. Then sonicated at a certain temperature. The $\mathrm{pH}$ was adjusted to 7 , centrifuged and the supernatant was retained. We next added $95 \%$ ethanol at ratio of $1: 4(v / v)$ at $4{ }^{\circ} \mathrm{C}$. The solution was thoroughly mixed, and then centrifuged (relative centrifugal force $=5000 \times \mathrm{g}$ ). The supernatant was discarded. The precipitate was dissolved in 0.1 M PBS (pH 6.0).

Single factor optimization and response surface experiments were performed to determine the appropriate ratio of material to liquid, amount of added sodium hydroxide, ultrasonic temperature, and ultrasonic time. Use Bradford protein analysis kit to measure the concentration of extracted protein with BSA protein standard, and calculate the protein extraction rate. Determine the best extraction conditions.

Corn gluten meal was pretreated following Wang et al. (2019a). The caseinate was dissolved in phosphate buffer to a concentration of $2 \%$, and then treated. Next, enzymatic hydrolysis was performed. Finally, activated carbon was used to adsorb the aromatic amino acids released in the enzymatic hydrolyzate. Activated carbon was added at a solid-to-liquid ratio of 1:10 ( $\mathrm{pH} 4.5$ ), and allowed to stand at room temperature for 12 hours. The activated carbon was then removed by filtration, and ultrafiltration (Kong et al., 2019) was used to obtain the HFOPs.

\subsection{Effects of enzyme specificity on the preparation of HFOPs}

We next investigated the effects of enzyme specificity on the preparation of HFOPs. In the first step of enzymatic hydrolysis, we used an alkaline protease, as is typical; alkaline proteases have a wide range of cleavage sites and a high level enzyme activity, and thus thoroughly hydrolyze proteins to form smaller peptides. The second step of enzymatic hydrolysis was carried out using cpAR, as well as either flavourzyme or papain; flavourzyme and papain have been used in many previous studies. cpAR has high specificity for aromatic and hydrophobic amino acids, while flavourzyme and papain have broad-spectrum substrate
Table 2. The combination of raw material and enzymes.

\begin{tabular}{cccc}
\hline Number & $\begin{array}{c}\text { Raw } \\
\text { material }^{+}\end{array}$ & $\begin{array}{c}\text { The first step of } \\
\text { enzymatic hydrolysis }\end{array}$ & $\begin{array}{c}\text { The second step of } \\
\text { enzymatic hydrolysis }\end{array}$ \\
\hline 1 & I & A & B \\
2 & I & A & C \\
3 & I & A & D \\
4 & II & A & B \\
5 & II & A & C \\
6 & II & A & D \\
7 & III & A & B \\
8 & III & A & C \\
9 & III & A & D \\
\hline
\end{tabular}

${ }^{*}$ I indicates chlorella powder; II indicates corn gluten meal; III indicates caseinate. A indicates alkaline protease; $B$ indicates cpAR; $C$ indicates papain; $D$ indicates flavourzyme.

reactivity. The combinations of raw materials and enzymes used in the enzymatic experiments are given in Table 2.

The amounts of various enzymes added were consistently $1 \%(w / v)$. All enzymatic reactions were allowed to proceed for 4 hours at the optimal temperature and $\mathrm{pH}$. Changes in $\mathrm{pH}$ were monitored during hydrolysis, and adjusted using $1 \mathrm{~mol} / \mathrm{L}$ $\mathrm{NaOH}$. When the reaction was completed, the reaction system was immediately placed in a boiling water bath for 5 minutes to terminate the reaction.

\subsection{Fischer ratio determination}

Amino acid concentrations in each sample were detected using high performance liquid chromatography, following Yang et al. (2011). First, prepare reagents. OPA derivatization reagent is $0.02014 \mathrm{~g}$ OPA dissolved in $1 \mathrm{~mL}$ methanol, then add $1 \mathrm{~mL} \beta$-mercaptoethanol, and then dilute to $5 \mathrm{~mL}$ with methanol. The $\mathrm{pH} 10.4$ borate buffer is $6.194 \mathrm{~g}$ boric acid and $6.524 \mathrm{~g}$ potassium hydroxide dissolved in $200 \mathrm{~mL}$ ultrapure water, and the $\mathrm{pH}$ is adjusted to 10.4 with metaphosphoric acid. The $\mathrm{pH} 5.8$ $25 \mathrm{mmol} / \mathrm{L}$ sodium acetate buffer is $2.0525 \mathrm{~g}$ anhydrous sodium acetate dissolved in ultrapure water and dilute to $1 \mathrm{~L}$, adjust the pH to 5.8 with $2 \%$ acetic acid.

Each sample was hydrolyzed using $6 \mathrm{M} \mathrm{HCl}$ at $110^{\circ} \mathrm{C}$ for 24 hours prior to the assay. Calculate the Fischer ratio of the sample. Then take $100 \mathrm{mgL}$ of the sample in a $2 \mathrm{~mL}$ centrifuge tube, add $300 \mu \mathrm{L}$ of OPA derivatization reagent with $\beta$-mercaptoethanol, $600 \mu \mathrm{L}$ of borate buffer, vortex, filter with $0.22 \mu \mathrm{m}$ organic filter, and let it stand for 15 minutes sample injection analysis.

A Thermo Fisher Scientific high performance liquid chromatography (UltiMate 3000 , Thermo Fisher Scientific, MA, US) equipped with a fluorescence detector was used for analysis, and $\mathrm{a} \mathrm{C}_{18}(4.6 \times 100 \mathrm{~mm}, 3.5 \mu \mathrm{m}, \mathrm{ZORBAX}$ Eclipse, Agilent, CA, US) column was used for separation. The fluorescence detection conditions are Em $450 \mathrm{~nm}$ and Ex $340 \mathrm{~nm}$. The column temperature was $32{ }^{\circ} \mathrm{C}$, the flow rate was $1 \mathrm{~mL} / \mathrm{min}$, and the injection volume was $10 \mu \mathrm{L}$. The mobile phase $\mathrm{A}$ is $\mathrm{pH} 5.8$ $25 \mathrm{mmol} / \mathrm{L}$ sodium acetate buffer: tetrahydrofuran $=95: 5(v: v)$ for preparation, and it is prepared during use. Mobile phase B is 
methanol. The gradient elution conditions was applied as follows: $10-28 \%$ B from 0 to $6 \mathrm{~min}, 28-30 \%$ B from 6 to $10 \mathrm{~min}, 30-35 \%$ B from 10 to $11 \mathrm{~min}, 35-37 \%$ B from 11 to $15 \mathrm{~min}, 37-47 \%$ B from 15 to $17 \mathrm{~min}, 47-55 \% \mathrm{~B}$ from 17 to $20 \mathrm{~min}, 55-65 \%$ B from 20 to $25 \mathrm{~min}, 65-10 \%$ B from 25 to $26 \mathrm{~min}$, and $10 \%$ B from 26 to $30 \mathrm{~min}$. All samples were tested in triplicate.

\subsection{Molecular weight distribution analysis}

The molecular weight distribution was determined with size exclusion chromatography using a Shimadzu high performance liquid chromatography system (HW-2000 GPC, Shimadzu, Kyoto, Japan), equipped with a aqueous gel column (TSKgel GMPWXL, Tosoh, Yamaguchi Prefecture, Japan). We used $0.1 \mathrm{~N}$ sodiumnitrate $\left(\mathrm{NaNO}_{3}\right)$ and an aqueous solution of $0.06 \%$ sodium azide $\left(\mathrm{NaN}_{3}\right)$ as eluents. The injection volume was $20 \mu \mathrm{L}$, the flow rate was $600 \mu \mathrm{L} / \mathrm{min}$, and the column temperature was $35^{\circ} \mathrm{C}$. Elution was monitored with a refractive index detector. The sample solution was filtered through a $0.22 \mu \mathrm{m}$ microfiltration membrane. The column was calibrated using a narrowly-distributed polyethylene glycol (PEG) standard set.

\subsection{Analysis by high performance liquid chromatography-electrospray ionization tandem mass spectrometry (LC-ESI-MS/MS)}

The peptidome was determined using an Ultimate 3000 system coupled to a Q Exactive Hybrid Mass Spectrometer (Quadrupole-Orbitrap, Thermo Fisher Scientific, MA, US), with an Electrospray ionization (ESI) nanospray source. The separation was performed using a $150 \mu \mathrm{m} \times 15 \mathrm{~cm}$ column (produced in house) packed with reversed-phase $\mathrm{C}_{18}-\mathrm{AQ}$ resin $(1.9 \mu \mathrm{m}, 100 \AA$ Å, ReproSil-Pur, Dr. Maisch GmbH, Stuttgart, Germany).

After reducing the sample at $37^{\circ} \mathrm{C}$ with $10 \mathrm{mM}$ dithiothreitol (DTT) for 4 hours, the sample was alkylated with $50 \mathrm{mM}$ iodoacetamide (IAA) at room temperature in the dark for $40 \mathrm{~min}$. The extracted peptides were then lyophilized to near dryness. The peptides were resuspended in $2-20 \mu \mathrm{L}$ of $0.1 \%$ formic acid before LC-MS/MS analysis.

Each sample was analyzed at a flow rate of $600 \mathrm{NL} / \mathrm{min}$, and the injection volume was $5 \mu \mathrm{L}$. The mobile phase $\mathrm{A}$ was composed of $0.1 \%$ formic acid and $2 \%$ acetonitrile aqueous solution, and the mobile phase $\mathrm{B}$ was composed of $0.1 \%$ formic acid and $80 \%$ acetonitrile aqueous solution. The elution conditions was applied as follows: $6-9 \% \mathrm{~B}$ from 0 to $8 \mathrm{~min}, 9-14 \% \mathrm{~B}$ from 8 to $24 \mathrm{~min}, 14-30 \%$ B from 24 to $60 \mathrm{~min}, 30-40 \%$ B from 60 to $75 \mathrm{~min}$ and $40-95 \% \mathrm{~B}$ from 75 to $80 \mathrm{~min}$. The parameters of the first-order mass spectrometry are as follows: Resolution: 70000, AGCtarget: 3e6, MaximumIT: 40 ms, Scanrange: 350 to $1800 \mathrm{~m} / \mathrm{Z}$. The mass spectrum parameters are as follows: Resolution: 75000, AGCtarget: 1e5, MaximumIT: $60 \mathrm{~ms}$, TopN: $60 \mathrm{~ms}$, NCE/s teppedNCE: 27 . The original mass spectrometry was performed by manual deconvolution. Twenty of the strongest peptide ions were selected from the preview scan of Orbitrap. All samples were run in triplicate.

\subsection{Statistical analyses}

The peak areas of identified peptides in the HFOPs were calculated based on the extracted ion chromatograms. The relative concentration of each peptide was calculated by dividing peak area of a peptide by the total peak areas of all identified peptides in corresponding sample. The identified peptides were classified based on amino acid composition and peptide chain length.

We used analyses of variance (ANOVAs) and Duncan's multiple range tests to identify significant differences and to discriminate among mean values. We considered $\mathrm{P}<0.05$ statistically significant. All values are shown as the means of three different tests with duplicate treatments per experiment. All statistical analyses were performed with SPSS (Statistical Package for the Social Sciences (SPSS) for Windows, Version 17.0, SPSS, Chicago, IL, USA, 2008).

\section{Results}

\subsection{Optimization of the conditions for protein extraction from Chlorella powder}

The single factor results of chlorella protein extraction are shown in Figure 1, and the optimal extraction conditions are as follows. The ratio of material to liquid is 1:40; the amount of sodium hydroxide added is $5 \%$; the ultrasonic temperature is $40^{\circ} \mathrm{C}$; the ultrasonic time is $60 \mathrm{~min}$. (Supplementary Material Table S1-S4 for specific data).

Based on the results of the single factor experiments, we selected an optimal material-to-liquid ratio, amount of added sodium hydroxide, and sonication temperature. We then designed 17 sets of experiments using State-Ease ("User's Guide," Version 8.0.7.1, Design Expert Software, Inc., Minneapolis.). The results of these experiments are shown in Table 3. The 3D surface map and the contour map among factors are shown in Figure S1.

A model, based on these experiments, was successfully constructed using Design-Expert. The regression equation (representing protein extraction rate) was $11.47+0.37 * \mathrm{~A}+0.66$ ${ }^{*} \mathrm{~B}+0.41{ }^{*} \mathrm{C}+0.39{ }^{*} \mathrm{~A} * \mathrm{~B}+0.26{ }^{*} \mathrm{~A} * \mathrm{C}-0.62{ }^{*} \mathrm{~B}{ }^{*} \mathrm{C}-0.38$ ${ }^{*} \mathrm{~A}^{2}-1.08{ }^{*} \mathrm{~B}^{2}-0.76{ }^{*} \mathrm{C}^{2}$, where $\mathrm{A}$ was the ratio of material to liquid; $\mathrm{B}$ was the amount of sodium hydroxide added; and $\mathrm{C}$ was the ultrasonic temperature. The optimal protein extraction conditions were determined. The ratio of solid to liquid was $1: 48(\mathrm{~m} / \mathrm{v})$; the amount of sodium hydroxide added was $5.4 \%$; and the sonication temperature was $43^{\circ} \mathrm{C}$. The protein extraction rate obtained under the optimal conditions was $11.20 \%$, similar to the model estimate (11.78\%).

\subsection{The effect of enzyme specificity on Fischer ratio}

In this study, we used various enzymes for the third step of enzymatic hydrolysis, including cpAR, papain, and flavourzyme. In addition to Chlorella powder, corn protein powder and caseinate were also used. We analyzed the preparation of HFOPs using different exopeptidases and different starting materials (Figure 2). For the raw material of chlorella powder, the Fischer ratio of the oligopeptide prepared by CPAR is as high as 37.39 , compared with the Fischer ratio increased by $40.00 \%$ prepared by papain, 


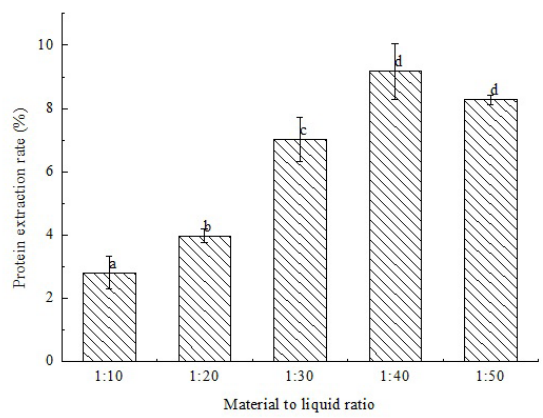

(a)

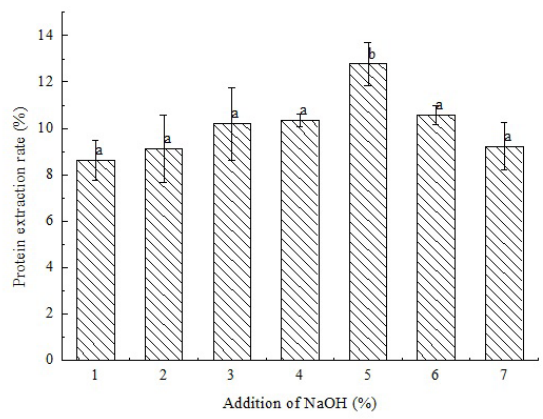

(b)

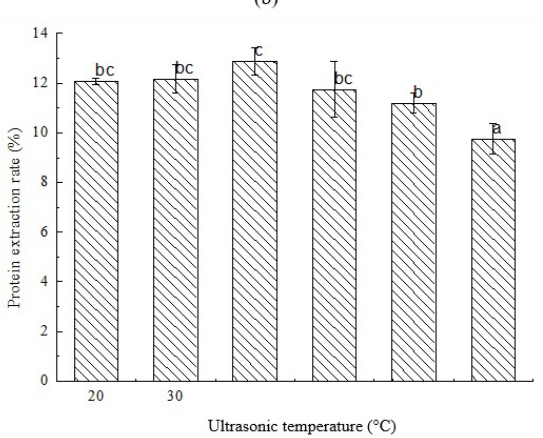

(c)

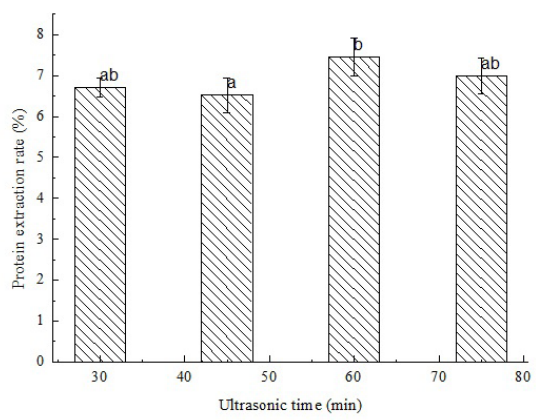

(d)

Figure 1. Single factor experiment of chlorella protein extraction. (a) Single factor experiment results of material-liquid ratio; (b) Single factor experiment results of the $\mathrm{NaOH}$ addition; (c) Single factor experimental results of ultrasonic temperature; (d) Single factor experiment results of ultrasound time. compared with the Fischer ratio increased by $51.68 \%$ prepared by flavourzyme. For the raw material of corn protein powder, the Fischer ratio of the oligopeptide prepared by CPAR is as high as 31.75 , compared with the Fischer ratio increased by $64.94 \%$ prepared by papain, compared with the Fischer ratio increased by $64.25 \%$ prepared by flavourzyme. For the raw material of caseinate, the Fischer ratio of the oligopeptide prepared by CPAR is as high as 35.03, compared with the Fischer ratio increased by $136.53 \%$ prepared by papain, compared with the Fischer ratio increased by $109.89 \%$ prepared by flavourzyme. It found that the Fischer ratio of the oligopeptides prepared using cpAR was significantly better than those of the oligopeptides prepared using papain and flavourzyme.

\subsection{Effects of enzyme specificity on peptide molecular weight}

The molecular weight distributions of the produced oligopeptides in solution were obtained using HW-2000 GPC chromatography. The retention time of the produced oligopeptide prepared by cpAR was slightly earlier than that of the produced oligopeptides prepared by papain and flavourzyme, indicating that the molecular weight of theproduced oligopeptide prepared by cpAR was larger (Figure 3 ).

The results of the statistical analyses of the molecular weight distributions are shown in Table 4. When Chlorella powder was used as the raw material, most of the oligopeptides prepared by cpAR had molecular weights of $1-2 \mathrm{kDa}(66.53 \%)$. In contrast, most of the produced oligopeptides prepared by flavourzyme and papain had molecular weights less than $1 \mathrm{kDa}(73.89 \%$ and $63.06 \%$, respectively). Obviously more of the oligopeptides with weights greater than $2 \mathrm{kDa}$ were produced with $\mathrm{cpAR}$ $(4.77 \%)$ than with either flavourzyme or papain $(0.14 \%$ and $0.45 \%$, respectively).

When oligopeptides were prepared from corn protein powder, we found that most oligopeptides produced using cpAR, flavourzyme, and papain have molecular weights of $1-2 \mathrm{kDa}$, (65.59\%, 67.42\%, and 69.01\%, respectively). However, the abundances of oligopeptides with molecular weights above $2 \mathrm{kDa}$ and below $1 \mathrm{kDa}$ differed noticeably among the three enzymes. It found that $16.62 \%$ of the produced oligopeptides prepared by cpAR had molecular weights above $2 \mathrm{kDa}$. Obviously lower percentages of the produced oligopeptides prepared by flavourzyme and papain had molecular weights above $2 \mathrm{kDa}$ (2.70\% and 2.67\%, respectively). Conversely only $17.80 \%$ of the produced oligopeptides prepared by cpAR had molecular weights below $1 \mathrm{kDa}$. Obviously greater percentages of the produced oligopeptides prepared by flavourzyme and papain had molecular weights below $1 \mathrm{kDa}(29.87 \%$ and $28.32 \%$, respectively, $\mathrm{p}<0.05)$.

When oligopeptides were prepared from casein protein, most of the oligopeptides prepared using cpAR had molecular weights of $1-2 \mathrm{kDa}(63.53 \%)$, while most of the oligopeptides prepared using flavourzyme and papain had molecular weights below $1 \mathrm{kDa}(80.28 \%$ and $82.75 \%$, respectively). We found that $2.32 \%$ of the produced oligopeptides prepared by cpAR had molecular weights above $2 \mathrm{kDa}$; this was obviously greater than the relative abundance of oligopeptides prepared by flavourzyme 
Table 3. Response surface experiment results of chlorella protein extraction.

\begin{tabular}{|c|c|c|c|c|}
\hline Experimental group & Material to liquid ratio & $\begin{array}{c}\text { Sodium hydroxide addition } \\
\text { (\%) }\end{array}$ & Sonication temperature $\left({ }^{\circ} \mathrm{C}\right)$ & Protein extraction rate (\%) \\
\hline 1 & $1: 40$ & 4 & 50 & 9.69 \\
\hline 2 & $1: 50$ & 5 & 30 & 9.67 \\
\hline 3 & $1: 40$ & 5 & 40 & 11.87 \\
\hline 4 & $1: 30$ & 4 & 40 & 9.34 \\
\hline 5 & $1: 40$ & 5 & 40 & 10.98 \\
\hline 6 & $1: 50$ & 4 & 40 & 8.36 \\
\hline 7 & $1: 30$ & 5 & 30 & 9.18 \\
\hline 8 & $1: 40$ & 6 & 50 & 8.30 \\
\hline 9 & $1: 40$ & 5 & 40 & 11.92 \\
\hline 10 & $1: 50$ & 5 & 50 & 12.38 \\
\hline 11 & $1: 30$ & 6 & 40 & 11.31 \\
\hline 12 & $1: 30$ & 5 & 50 & 10.48 \\
\hline 13 & $1: 50$ & 6 & 40 & 11.46 \\
\hline 14 & $1: 40$ & 5 & 40 & 10.98 \\
\hline 15 & $1: 40$ & 5 & 40 & 11.59 \\
\hline 16 & $1: 40$ & 4 & 30 & 10.67 \\
\hline 17 & $1: 40$ & 6 & 30 & 10.80 \\
\hline
\end{tabular}

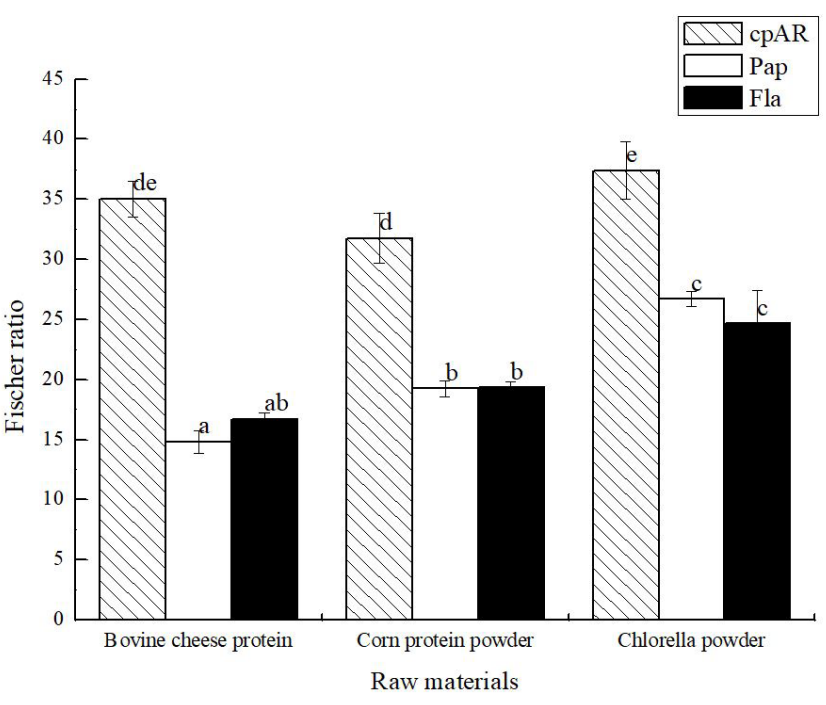

Figure 2. Results of preparing HFOP using different exopeptidases from different raw materials.

and papain with molecular weights greater than $2 \mathrm{kDa}(0.07 \%$ and $0.02 \%$, respectively, $\mathrm{p}<0.01$ ).

The molecular weight distribution of the oligopeptides produced using the enzyme cpAR, which has a high specificity for certain aromatic amino acids, differed from those of the commonly used enzymes flavourzyme and papain (Table 4). Oligopeptides prepared with specific enzymes have higher molecular weights. cpAR only cleave aromatic amino acids.
Compared to flavourzyme and papains, specific enzymes have fewer cleavage sites and therefore contribute a little to the reduction of molecular weight. However, because the specific enzyme cpAR efficiently cleaves aromatic amino acids, this enzyme effectively removes aromatic amino acids. Therefore, compared to oligopeptide production using enzymes with a wide range of cleavage sites, oligopeptide Fischer ratios can be effectively increased by using specific enzymes in oligopeptide preparation.

\subsection{Analysis of the prepared HFOPs sequences}

The sequences of the HFOPs obtained by hydrolyzing chlorella powder with the mutant cpAR enzyme were determined using LC-ESI-MS/MS. The total ion current chromatogram is provided in Figure S2.

The amino acid composition and the length of the peptide chain were analyzed (Figure 4).

Peptide chains containing branched-chain amino acids without aromatic amino acids were most abundant (48.31\%), while peptides containing aromatic amino acids but not branched-chain amino acids were least abundant (11.36\%). Some peptides contained branched-chain amino acids as well as aromatic amino acids. Therefore, branched-chain amino acids were significantly more abundant than aromatic amino acids, consistent with the Fischer ratio. Peptide chains of 7-9 amino acids were most common (51.38\%), followed by peptide chains of $4-6$ amino acids (38.30\%), and peptide chains of 10 amino acids (10.32\%). Most peptide chains were 7-9 amino acids long. Previously, Li et al. (2019) prepared oligopeptides with molecular weights primarily distributed between $180 \mathrm{Da}$ and $500 \mathrm{Da}$, with peptide chain lengths of about 


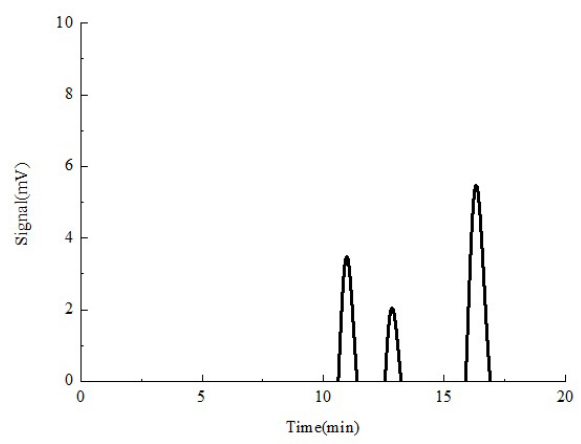

(a)

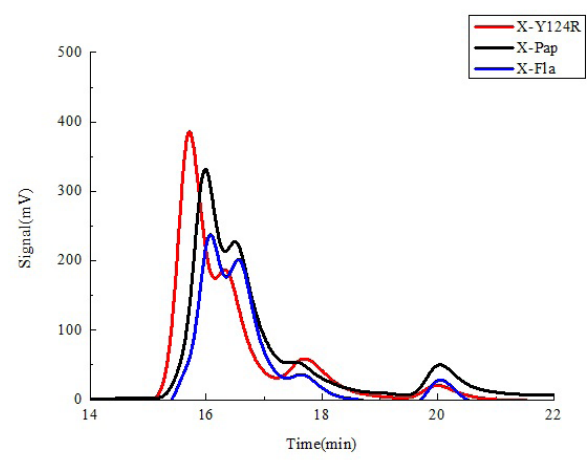

(b)

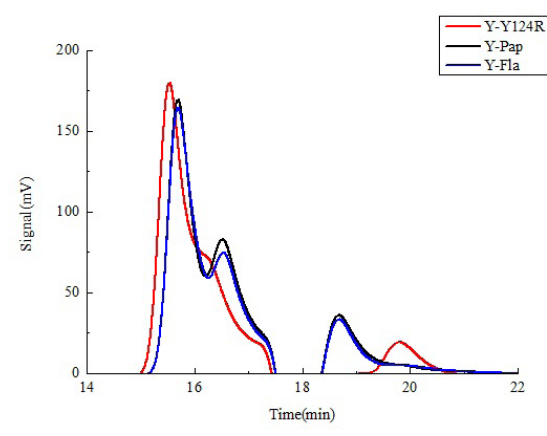

(c)

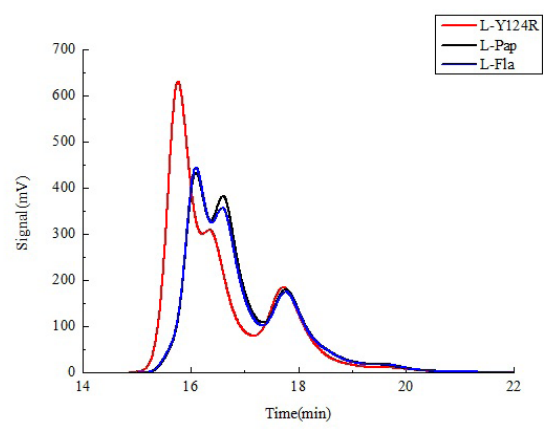

(d)

Figure 3. Molecular weight distribution profiles of oligopeptides prepared from different raw materials and different enzymes. (a) polyethylene glycol (PEG) standards; (b) oligopeptides from chlorella powder using different enzymes; (c) oligopeptides from corn protein powder using different enzymes; (d) oligopeptides from caseinate using different enzymes.
2-5 amino acids. Similarly, Xu et al. (2012) prepared oligopeptides with molecular weights primarily distributed between $300 \mathrm{Da}$ and $600 \mathrm{Da}$, with peptide chain lengths of about 3-6 amino acids. Although the oligopeptides prepared herein were longer than those prepared previously, these oligopeptides still did not exceed 10 amino acids in length. The main peptide sequence is shown in Table 5 . The oligopeptides prepared in this study were primarily seven to nine amino acids long and included more branched-chain amino acids than aromatic amino acids.

\section{Discussion}

\subsection{Raw material}

When preparing HFOPs, the selection of the raw material is extremely important. The protein content and amino acid composition of the raw material, especially the relative abundances of branched-chain and aromatic amino acids, strongly affect the process of HFOPs production (We et al., 2014).

The plant-derived raw material commonly used to prepare HFOPs is corn gluten meal, which has a protein content of $65 \%$; the relative abundances of branched-chain and aromatic amino acids in this material are listed in Table 6. As can be seen from the table, corn gluten meal contains more branched chain amino acids and fewer aromatic amino acids. The relative leucine content in corn gluten meal was $43.62 \%$, while the Fischer ratio of this material was 3.21 .

The animal-derived raw material commonly used to prepare HFOPs is cow casein, which is the source of $80-82 \%$ of the total protein in milk (Li, 2002). In casein, branched-chain amino acids were more abundant than aromatic amino acids. The Fischer ratio of this material was 2.51 .

At present, the raw materials used to prepare HFOPs are typically derived from animals or plants; proteins of microbial origin are less commonly used. We selected the microbe Chlorella as the raw material for the preparation of HFOPs. The relative abundances of aromatic and branched-chain amino acids were compared among Chlorella powder, corn protein powder, and caseinate. The amino acid composition of Chlorella powder, corn protein powder, and caseinate is shown in Table S5.

The relative abundances of branched-chain and aromatic amino acids in the Chlorella protein are shown in Table 6. The original Fischer ratio of the Chlorella protein was 2.47, similar to the Fischer ratios of caseinate and corn protein powder. The relative abundance of branched-chain amino acids, was firstly analyzed. The result shown that isoleucine was more abundant in Chlorella powder than in corn protein powder, but less abundant in Chlorella powder than in caseinate. For leucine, it was more abundant in Chlorella powder than in caseinate, but less abundant in Chlorella powder than in corn protein powder. The content of valine is opposite, it was more abundant in Chlorella powder than in corn protein powder and caseinate (although valine levels were similar in Chlorella powder and caseinate). 
Table 4. Molecular weight distribution of oligopeptides prepared by different raw materials with different enzymes.

\begin{tabular}{|c|c|c|c|c|c|c|c|c|c|}
\hline \multirow{2}{*}{ MW (kDa) } & \multicolumn{3}{|c|}{ Chlorella powder } & \multicolumn{3}{|c|}{ Corn protein powder } & \multicolumn{3}{|c|}{ Caseinate } \\
\hline & $\mathrm{X}-\mathrm{Y} 124 \mathrm{R}$ & X-Fla & X-Pap & Y-Y124R & Y-Fla & Y-Pap & L-Y124R & L-Fla & L-Pap \\
\hline$>3$ & $0 \%$ & $0 \%$ & $0 \%$ & $0.19 \%$ & $0 \%$ & $0 \%$ & $0 \%$ & $0 \%$ & $0 \%$ \\
\hline $2-3$ & $4.77 \%$ & $0.14 \%$ & $0.45 \%$ & $16.43 \%$ & $2.70 \%$ & $2.67 \%$ & $2.32 \%$ & $0.07 \%$ & $0.02 \%$ \\
\hline $1-2$ & $66.53 \%$ & $25.97 \%$ & $36.49 \%$ & $65.59 \%$ & $67.42 \%$ & $69.01 \%$ & $63.53 \%$ & $19.65 \%$ & $17.22 \%$ \\
\hline$<1$ & $28.70 \%$ & $73.89 \%$ & $63.06 \%$ & $17.80 \%$ & $29.87 \%$ & $28.32 \%$ & $34.15 \%$ & $80.28 \%$ & $82.75 \%$ \\
\hline
\end{tabular}

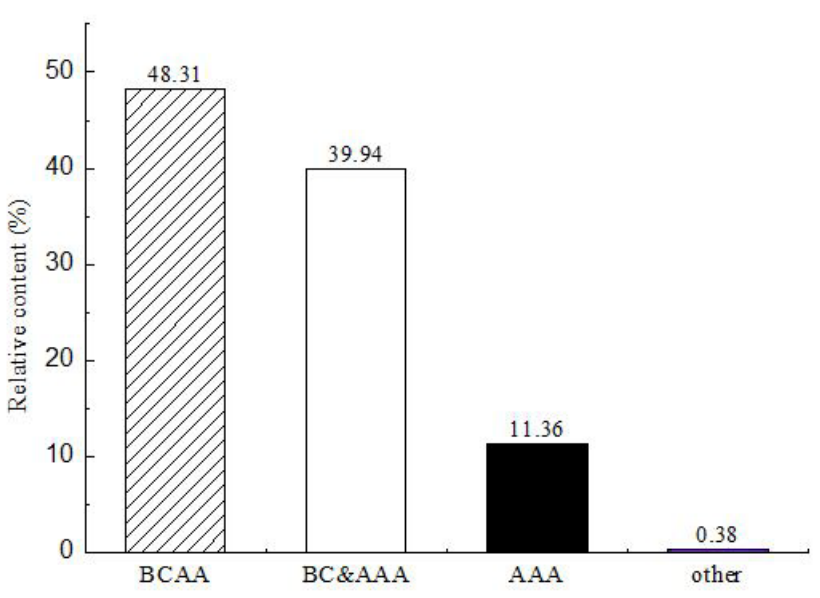

(a)

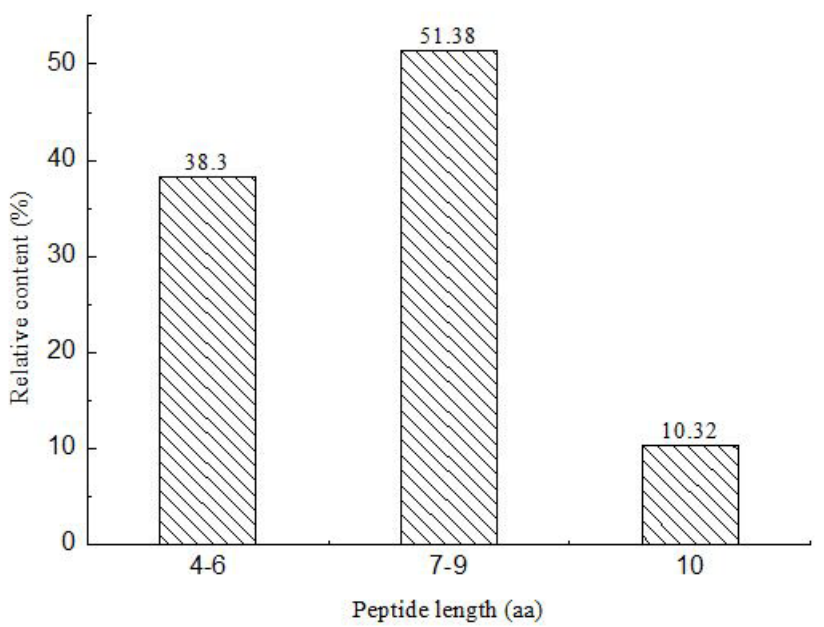

(b)

Figure 4. Peptide analysis of HFOPs prepared by hydrolysis of chlorella powder with cpAR enzyme. (a) Amino acid composition; (b) peptide chain length.

Next, we analyzed the relative abundances of aromatic amino acids. Of these, tyrosine was less abundant in Chlorella powder than in corn protein powder or caseinate (although tyrosine levels were similar in Chlorella powder and caseinate). Phenylalanine was more abundant in Chlorella powder than in corn protein powder or caseinate, while tryptophan was more abundant in Chlorella powder than in corn protein powder, but less abundant in Chlorella powder than in caseinate. Thus, Chlorella proteins may be potentially advantageous in the preparation of HFOPs. Our experimental results indicated that the Chlorella protein had certain advantages when used for the preparation of HFOPs. When chlorella powder is used as the raw material, whether the second step of enzymatic hydrolysis is using cpAR or papain or flavourzyme, the Fischer ratio of the preparing oligopeptides are higher than 20. Higher Fischer ratio oligopeptides are easier to produce than corn protein powder and caseinate.

When preparing HFOPs, the characteristics of the available raw materials, including protein content, amino acid composition, and original Fischer ratio, should be carefully considered. Raw materials with high protein content and high Fischer ratios may potentially be used to prepare HFOPs.

\subsection{Specific enzymatic hydrolysis}

Most previous studies have used various combinations of common proteases to optimize process conditions and produce oligopeptides with high Fischer ratios. However, studies using similar materials have sometimes generated conflicting results. To address this problem, we hypothesized that targeted enzymatic hydrolysis, which would effectively remove aromatic amino acids, would increase the Fischer ratios of the produced oligopeptides.

Lan et al. (2019) used alcalase and flavorzyme to prepare a Antarctic krill oligopeptide with a Fischer ratio of 21.12, while $\mathrm{Xu}$ et al. (2017) used alkaline protease and papain to prepare HFOPs from corn gluten meal. The alcalase, flavorzyme, alkaline proteases and papain used in these previous studies have wide ranges of cleavage sites, and the effects of directed enzymatic hydrolysis is poor.

Ren et al. (2016) used alcalase AF 2.4 L and carboxypeptidase A to prepare a mixture of oligopeptides with a Fischer ratio of 31.92 from Whitmania pigra proteins. While Li et al. (2019) used $\alpha$-chymotrypsin and carboxypeptidase A to prepare a maize oligopeptide with a Fischer ratio of 41.87 and a less bitter taste. The $\alpha$-chymotrypsin and carboxypeptidase A specifically react with aromatic amino acids, resulting in directed digestion. Thus, oligopeptides hydrolyzed using enzymes specific to aromatic amino acids have somewhat improved Fischer ratios.

In this study, the extracted Chlorella protein was hydrolyzed using alkaline protease and the cpAR recombinant mutant enzyme derived from Aspergillus niger M0988. The liquid 
Original Article

Xiong et al.

Table 5. Main peptide sequence of HFOPs prepared by cpAR mutant enzymatic hydrolysis of chlorella powder.

\begin{tabular}{|c|c|c|c|c|}
\hline \multicolumn{5}{|c|}{ "BCAA-containing-oligopeptides } \\
\hline EDAVTLRTR & TLRLA & EVLRNLKS & NVLPNLHNT & GPDLLQL \\
\hline KVDPALKPT & EGLLNK & MPLEPLT & ALTV & LAENALATVP \\
\hline LGENSLLGR & LAGSL & LVGQDL & VLAGSL & DGLLLPR \\
\hline LVGQDL & LEPVT & PLLVENHSV & LMKLMKL & VPAPTVL \\
\hline TVEL & KLSLVHTPN & LPVPQ & EDLVNKSV & LVDVTVNVT \\
\hline MLEPSLKA & KKLEAGL & MPALVVLKN & LPPL & KNLKLLPDQ \\
\hline VLTNPLVRT & MGLPVGQL & VPGLVAK & KAVL & LDLAKTVNL \\
\hline EDDLLK & MPALVVR & PALVVR & LPAL & LPSL \\
\hline LTNPLLSR & TMLLEKVP & LDLVNKV & TQVLDDVTNT & QTNMVKL \\
\hline VMPALVVR & APKLGPLGL & TAMELKVGL & KPLL & KLLKPL \\
\hline KLVMVEKL & LMSTP & LSLKL & RLPNLNHT & VVVGL \\
\hline LNKDPLQL & AVNLCR & LTPL & APLAKVV & LLEVPKQL \\
\hline RKLPT & KVAAVVL & VEPVHV & HLLGGPHL & KALMEK \\
\hline TLKPP & VLEDKLVV & PGDGLRLL & LTSLKALKD & \\
\hline \multicolumn{5}{|c|}{ *BCAA\&AAA-containing-oligopeptides } \\
\hline RQSWTLMVH & TGSDALFWKK & EFENKNLYHL & DLGFNKYR & WLQVKLPVV \\
\hline QKGPVNVLSF & EKLY & VPAF & TDGLDKF & QNLCYLAP \\
\hline EFENNKLY & APKLSY & SGLAPYALT & VNDLFER & VGFSAFKV \\
\hline FLFVFGYT & APTLKY & APKLSY & TASKLFMR & LPVF \\
\hline KTDKLSSKF & EELNF & VGFGTFK & KVELDSF & EVGFNKYR \\
\hline LFGPVC & LFQKLTHLT & KVKHTFL & WLAEPKASSL & WLFWQK \\
\hline KSYLSKL & LTSLKWVAAL & KNFPVTAPGT & KDGYLLDL & PTEEFTKL \\
\hline MDLDFKK & PLLKNHF & VVAFLSSPL & FLGPVT & PTLKY \\
\hline APFGLALLAP & TLADFTYAQ & KSLF & WYSNKKL & DFNYLL \\
\hline YGFAVKVS & RKAFVS & NDSWVLLY & LVKPW & RTPVSMLTYT \\
\hline KFLT & KVELDSF & FNELGRML & TFVK & \\
\hline \multicolumn{5}{|c|}{${ }^{*}$ AAA-containing-oligopeptides } \\
\hline KDKF & FDPENF & KPYPQ & WTKSF & FNESKGGF \\
\hline KPGRMNY & EFENK & KDKFAA & KTGKFR & KYYN \\
\hline \multicolumn{5}{|l|}{ KFSK } \\
\hline \multicolumn{5}{|l|}{ other oligopeptides } \\
\hline NKADKHAP & & & & \\
\hline
\end{tabular}

Table 6. Aromatic amino acids and branched chain amino acids in raw materials*.

\begin{tabular}{|c|c|c|c|c|c|c|}
\hline \multirow{2}{*}{ Amino acid } & \multicolumn{2}{|c|}{ Chlorella powder } & \multicolumn{2}{|c|}{ Corn protein powder } & \multicolumn{2}{|c|}{ Caseinate } \\
\hline & Content (\%) & Proportion (\%) & Content (\%) & Proportion (\%) & Content (\%) & Proportion (\%) \\
\hline Ile & 1.67 & 12.98 & 2.05 & 10.85 & 5.50 & 17.41 \\
\hline Leu & 4.08 & 31.70 & 8.24 & 43.62 & 8.30 & 26.27 \\
\hline Val & 2.52 & 19.58 & 3.00 & 15.88 & 6.50 & 20.57 \\
\hline Tyr & 1.77 & 13.75 & 2.31 & 12.23 & 5.70 & 18.04 \\
\hline Phe & 2.46 & 19.11 & 3.09 & 16.36 & 4.50 & 14.24 \\
\hline $\operatorname{Trp}$ & 0.37 & 2.87 & 0.20 & 1.06 & 1.10 & 3.48 \\
\hline $\mathrm{F}$ & \multicolumn{2}{|c|}{2.47} & \multicolumn{2}{|c|}{3.21} & \multicolumn{2}{|c|}{2.51} \\
\hline
\end{tabular}

*The content is a percentage of the total protein. The proportion is the percentage of aromatic amino acids and branched chain amino acids. 
Fischer ratio of the oligopeptide, after activated carbon adsorption and ultrafiltration, was 37.39. As this Fischer ratio was greater than 20 , we considered it relatively high. Our experimental results indicated that the cpAR enzyme generated an oligopeptide with an obviously better Fischer ratio than the oligopeptides generated using papain and flavourzyme, irrespective of the raw material used. Thus, targeted enzymatic hydrolysis generated HFOPs; cpAR was particularly effective. However, because specific enzymes tend to cleave molecules effectively, these enzymes do not effectively reduce molecular weight of proteins. Therefore, when selecting an enzyme for the preparation of HFOPs, the balance between Fischer ratio and molecular weight should be considered, and molecular weight should be maintained while the Fischer ratio is increased.

\subsection{Removal of aromatic amino acids}

Another key to achieving a high Fischer ratio is to reduce the aromatic amino acids content in the enzymatic hydrolysate while retaining the branched chain amino acid. At present, there are many methods for removing aromatic amino acids from HFOPs solutions, including gel filtration, membrane separation, pervaporation, and ion exchange. However, such methods are not suitable for industrial production as they are complicated, expensive, and low-yield. The activated carbon adsorption method is more suitable for the large-scale production of HFOPs because it is inexpensive, and the materials used for the simple adsorption process can be reused. Studies have shown that activated carbon has a high adsorption efficiency, and a very high affinity for hydrophobic compounds; aromatic and branched-chain amino acids are hydrophobic. Non-polar benzene ring side chains also interact with non-polar adsorption sites on the surface of the activated carbon. Thus, when both branched-chain and aromatic amino acids are present, activated carbon preferentially adsorbs the aromatic amino acids (Sun et al., 2013). For example, Lan et al. (2019) show that the resulting oligopeptides had a Fischer ratio of 21.12 after adsorption with activated carbon. Similarly, Studies by Sun et al. (2013) show that the aromatic amino acids could be effectively absorbed by the activated carbon under the appropriate conditions, which would contribute to a lot in the process of preparation of HFOPs.

The type of activated carbon, the ratio of activated carbon to hydrolyzate, and $\mathrm{pH}$ all affect the adsorption of aromatic amino acids by activated carbon. Li et al. (2019) showed that, compared to particulate or columnar activated carbon, powdered activated carbon more effectively removed aromatic amino acids while retaining branched-chain amino acids. Moreover, aromatic amino acids are more effectively adsorbed by activated carbon at an acidic pH (Jiang et al., 2017). Chu et al. (2012) used a 1:10 ratio of activated carbon to hydrolyzate for adsorption treatment, based on the removal rate of aromatic amino acids and the retention rate of branched chain amino acids. Here, following these previous studies, we performed activated carbon adsorption treatment to remove aromatic amino acids using powdered activated carbon with a large specific surface area at a ratio of 1:10 and a $\mathrm{pH}$ of 4.5 . The Fischer ratio of the final oligopeptide solution suggested that the activated carbon adsorption treatment effectively removed aromatic amino acids while retaining branched-chain amino acids.

\section{Acknowledgements}

This study was funded by the National Key R\&D Program of China (No. 2017YFC1600605), the National Natural Science Foundation (No. 31601408), the Beijing Natural Science Foundation (No. 6172003), and the Scientific \& technological innovation service capability construction project (No. PXM2018_014213_000033).

\section{References}

Appannagari, R. R. (2017). Environmental pollution causes and consequences: a study. North Asian International Research Journal of Social Science and Humanities, 3(8), 151-161.

Chu, J., Liu, J. W., Shi, J. G., Liu, K. C., Liu, Y. C., Zhao, Y. B., \& Wang, D. Y. (2012). Preparation of high fischer ratio oligo-peptide mixture with active carbon. Food Science and Technology, 248(6), 134-137.

Du, S., Song, R., \& Luo, H. (2014). High fischer ratio oligo-peptide from hydrolysates of tuna meat. Journal of Chinese Institute of Food Science and Technology, 14(10), 124-133.

Gerken, H., Donohoe, B., \& Knoshaug, E. (2013). Enzymatic cell wall degradation of Chlorella vulgaris and other microalgae for biofuels production. Planta, 237(1), 239-253. http://dx.doi.org/10.1007/ s00425-012-1765-0. PMid:23011569.

Ichikawa, K., Okabayashi, T., Shima, Y., Iiyama, T., Takezaki, Y., Munekage, M., Namikawa, T., Sugimoto, T., Kobayashi, M., Mimura, T., \& Hanazaki, K. (2012). Branched-chain amino acid-enriched nutrients stimulate antioxidant DNA repair in a rat model of liver injury induced by carbon tetrachloride. Molecular Biology Reports, 39(12), 10803-10810. http://dx.doi.org/10.1007/s11033-012-1974-4. PMid:23053977.

Jiang, W., Yang, Y., Tao, R., Jiang, X., Zhou, X., \& Zhou, Z. (2017). Preparation of a novel chitosan-based biosorbent cross-linked with phenethylamine for adsorption of aromatic amino acids. Carbohydrate Polymers, 176(22), 236-245. http://dx.doi.org/10.1016/j. carbpol.2017.08.067. PMid:28927604.

Kamalinejad, M., Jafari, J. M., Nayebi, N., Choopani, R., \& Adhami, S. (2018). dietary recommendation for management of malnutrition in cirrhosis based on iranian traditional medicine: a systematic. Review Journal of Research in Medical and Dental Science, 6(2), 494-500.

Kong, Y., Zhang, L. L., Zhao, J., Zhang, Y. Y., Sun, B. G., \& Chen, H. T. (2019). Isolation and identification of the umami peptides from shiitake mushroom by consecutive chromatography and LC-Q-TOFMS. Food Research International, 121(7), 463-470. http://dx.doi. org/10.1016/j.foodres.2018.11.060. PMid:31108770.

Lan, C., Zhao, Y. Q., Li, X. R., \& Wang, B. (2019). High Fischer ratio oligopeptides determination from Antartic krill: preparation, peptides profiles and in vitro antioxidant activity. Journal of Food Biochemistry, 43(5), e12827. http://dx.doi.org/10.1111/jfbc.12827. PMid:31353526.

Li, T., Tian, Y., Sun, F., Wang, Z., \& Zhou, N. (2019). Preparation of high Fischer's ratio corn oligopeptides using directed enzymatic hydrolysis combined with adsorption of aromatic amino acids for efficient liver injury repair. Process Biochemistry, 84(9), 60-72. http:// dx.doi.org/10.1016/j.procbio.2019.06.002.

Li, X. (2002). Structural characteristics of casein in cow's milk and its application. Food Industries, 15(15), 29-31. 
Merchant, R. E., \& Andre, C. A.. (2001). A review of recent clinical trials of the nutritional supplement Chlorella pyrenoidosa in the treatment of fibromyalgia hypertension and ulcerative colitis. Alternative Therapies in Health and Medicine, 7(3), 79-91. PMid:11347287.

Noguchi, N., Yanagita, T., Rahman, S., \& Ando, Y. (2016). chlorella protein hydrolysate attenuates glucose metabolic disorder and fatty liver in high-fat dietinduced obese mice. Journal of Oleo Science, 65(7), 613-620. PMid:27321121.

Qi, J., \& Kim, S. M. (2017). Characterization and immunomodulatory activities of polysaccharides extracted from green alga Chlorella ellipsoidea. International Journal of Biological Macromolecules, 95(3), 106-114. PMid:27856321.

Ren, Y., Yang, Y. J., Wu, W. J., Zhang, M. M., Wu, H., \& Li, X. F. (2016). Identification and characterization of novel anticoagulant peptide with thrombolytic effect and nutrient oligopeptides with high branched chain amino acid from Whitmania pigra protein. Amino Acids, 48(11), 2657-2670. http://dx.doi.org/10.1007/s00726-0162299-8. PMid:27487778.

Shen, W., \& Matsui, T. (2017). Current knowledge of intestinal absorption of bioactive peptides. Food \& Function, 8(12), 4306-4314. http:// dx.doi.org/10.1039/C7FO01185G. PMid:29139513.

Sun, N. X., Ye, C. J., Liu, Y. H., \& Wang, Y. X. (2013). Optimization of adsorption of aromatic amino acid by response surface methodology. Journal of Chemical Information and Modeling, 53(10), 1689-1699.

Wang, Y., Song, X., Feng, Y., \& Cui, Q. (2019a). Changes in peptidomes and Fischer ratios of corn-derived oligopeptides depending on enzyme hydrolysis approaches. Food Chemistry, 297(28), 124931. PMid:31253328.

Wang, Z. G., Ying, X. G., Wang, Y. F., Yu, X. W., \& Luo, H. Y. (2019b). Structural analysis and activity evaluation of high fischer ratio oligopeptides from minced meat of skipjack (Katsuwonus pelamis). Journal of Aquatic Food Product Technology, 28(10), 1063-1075.

We, R. B., Huang, C., Luo, H. Y., \& Song, R. (2014). Progress in preparation and application of high fischer ratio oligopeptides derived from food protein source. Shipin Kexue, 35(15), 289-294.

Xu, T., Sun, N., Liu, Y., Ye, C., Jiang, Z., Du, F., \& Wang, Y. (2017). Preparation of oligopeptides from corn gluten meal by two enzymes at one step using response surface methodology and investigation of their antifatigue activities. Biomedical Research, 28(1), 3948-3956.

Xu, W., Wang, X., \& Chi, Y. (2012). Preparation of oligopeptide mixture with a high Fischer ratio from egg white proteins. Applied Mechanics and Materials, 140(1), 406-410.

Yang, W., Xian, S., Li, D. X., \& Wan, X. C. (2011). RP-HPLC determination of seventeen free amino acids in tea with O-phthalaldehyde precolumn derivation. Chaye Kexue, 31(3), 211-217.

Zhang, Y., Wu, J., Xu, C., \& Zhou, M. (2019). Intelligent service system design of food therapy experience into chronic disease. In A. Marcus \& W. Wang (Eds.), Design user experience and usability application domains (pp. 382-392). Cham: Springer International Publishing. http://dx.doi.org/10.1007/978-3-030-23538-3_30. 


\section{Supplementary Material}

Supplementary material accompanies this paper.

Table S1 Single factor experiment results of chlorella flour protein extract material-to-liquid ratio

Table S2 Single factor experiment results of chlorella flour protein extract $\mathrm{NaOH}$ addition

Table S3 Single factor experiment results of chlorella flour protein extract ultrasonic temperature

Table S4 Single factor experiment results of chlorella flour protein extract ultrasonic time

Table S5 Amino acids content of raw materials

Figure S1 3D surface map and contour map between factors. A is the ratio of material to liquid; B is the amount of sodium hydroxide added; $\mathrm{C}$ is the ultrasonic temperature. (A) amount of sodium hydroxide added $\times$ ratio of material to liquid, (B) ultrasonic temperaturexratio of material to liquid and (C) ultrasonic temperature xamount of sodium hydroxide added on the extraction rate of protein. Not plotted variable is fixed at zero level in all of the three graphs.

Figure S2 Total ion current chromatogram of high Fischer ratio oligopeptide prepared from chlorella powder and cpAR

This material is available as part of the online article from http://www.scielo.br/cta 